\title{
Congenital Heart Defects in Monochorionic Twins: A Systematic Review and Meta-Analysis
}

\author{
Manon Gijtenbeek ${ }^{1, * \mathbb{D}}$, Maryam R. Shirzada ${ }^{1}$, Arend D. J. Ten Harkel ${ }^{2}$, Dick Oepkes ${ }^{1}$ and \\ Monique C. Haak ${ }^{1}$ \\ 1 Division of Fetal Medicine, Department of Obstetrics, Leiden University Medical Center, PO Box 9600, \\ NL-2300 RC Leiden, The Netherlands; m.r.shirzada@lumc.nl (M.R.S.); d.oepkes@lumc.nl (D.O.); \\ m.c.haak@lumc.nl (M.C.H.) \\ 2 Division of Pediatric Cardiology, Department of Pediatrics, Leiden University Medical Center, PO Box 9600, \\ NL-2300 RC Leiden, The Netherlands; A.D.J.ten_Harkel@lumc.nl \\ * Correspondence: m.gijtenbeek@lumc.nl; Tel.: +31-71-526-2095; Fax: +31-71-526-5413
}

Received: 20 May 2019; Accepted: 18 June 2019; Published: 24 June 2019

\begin{abstract}
Monochorionic (MC) twins are at an increased risk of developing congenital heart defects (CHDs) compared to singletons and dichorionic twins. The development of acquired CHDs in this specific group of twins is associated with twin-twin transfusion syndrome (TTTS). We performed a systematic review and meta-analysis to provide an overview of the reported birth prevalence of CHDs in liveborn MC twins with and without TTTS. Twelve studies were included in this review. Compared to the reference population, MC twins were 6.3 times more likely to be born with a CHD (59.3 per 1000 liveborn twins; relative risk (RR) 6.3; 95\% confidence interval (CI): 4.4-9.1), and TTTS twins had a 12-fold increased risk of having a CHD at birth (87.3 per 1000 live births; RR 12.4, 95\% CI: 8.6-17.8). The increased incidence of CHDs can mainly be attributed to the risk of right ventricular outflow tract obstruction (35/1000 TTTS twin live births vs. 0.5/1000 singleton live births). We recommend an expert fetal echocardiogram in all MC twins, follow-up scans in the event of TTTS, and a postnatal cardiac evaluation in all TTTS survivors.
\end{abstract}

Keywords: congenital heart defect; monochorionic twin pregnancy; prevalence; twin-twin transfusion syndrome; newborn

\section{Introduction}

Congenital heart defects (CHDs) represent the most common human birth defect, having a birth prevalence of 7-9 per 1000 singleton live births [1,2]. CHDs are more common in twin pregnancies with a reported prevalence of approximately 20 in 1000 live births. Monochorionic (MC) twins are at an even higher risk compared to dichorionic (DC) twins [2]. A systematic review and meta-analysis of four studies conducted in 2007 showed a 9-fold increase in CHD risk in MC twins [3] compared to singletons.

The development of acquired CHDs in MC twins is associated with twin-twin transfusion syndrome (TTTS) [4]. TTTS complicates 10-15\% of MC twin pregnancies and results from unbalanced blood flow from one twin (donor) to the other twin (recipient) via placental vascular anastomoses $[5,6]$. The birth prevalence of MC twins with a CHD may be influenced by the improved survival rates for MC twins over the last decade, especially for those treated for TTTS [7]. The literature has been significantly expanded and more up-to-date population prevalence rates have been published [1]. The aim of this systematic review and meta-analysis was to provide an updated overview of the reported birth prevalence of CHDs in liveborn MC twins with and without TTTS. 


\section{Methods}

\subsection{Search Strategy}

This systematic review was performed using the PRISMA methodology [8]. Relevant articles were identified using electronic databases (Pubmed, Embase, Web of Science, and Cochrane) on 17 January 2019, using search terms related to 'monochorionic twins' and 'congenital heart defects'. The search was limited to original research papers with English abstracts. No time restriction for publication dates was used. All titles and abstracts were screened for study population (liveborn MC twins), type of $\mathrm{CHD}$, and birth prevalence. Papers focusing on etiology, prenatal diagnosis, prognosis, or animal research were excluded. Two reviewers (M.G. and A.S.) screened titles and abstracts independently for relevance. If a title or abstract seemed relevant, full text was retrieved and assessed for inclusion. Articles were eligible if the number of liveborn MC twins affected by CHD could be determined from the published data, there was postnatal confirmation of the CHD, and chorionicity was determined. Selected articles were cross-referenced. Disagreement was resolved by consensus.

\subsection{Quality Assessment}

Study quality and risk of bias was assessed by the two reviewers using the Hayden bias rating tool [9], as suggested by the Cochrane Collaboration. With this tool the risk of bias was assessed in six domains (study participation, study attrition, prognostic factor measurement, outcome measurement, study confounding, and statistical analysis and reporting). Each of the six potential bias domains was rated as having high, moderate, or low risk of bias. Low methodological quality was not an exclusion criterion.

\subsection{Data Extraction}

Two reviewers (M.G. and A.S.) extracted the relevant information from the selected articles. The following study characteristics were extracted from the selected articles and tabulated: first author, year of publication, time period during which the study was performed, country, study design (retrospective or prospective), determination of chorionicity, number of live births, number of patients with CHD, birth prevalence of total CHDs, and prevalence of common CHD subtypes: right ventricular outflow tract obstruction (RVOTO), ventricular septal defect (VSD), atrial septal defect (ASD), coarctation of the aorta (CoA), aortic stenosis (AS), tetralogy of Fallot (TOF), and transposition of the great arteries (TGA).

\subsection{Statistical Analysis}

Statistical analyses were performed using MS excel for Windows (Microsoft Corporation, Redmond, Washington, DC, USA) and Review Manager 5.3 (Copenhagen: The Nordic Cochrane Center, The Cochrane Collaboration, 2014). Relative risks (RRs) and their $95 \%$ confidence intervals (CIs) were used as effect sizes for the meta-analysis of dichotomous data. Heterogeneity between studies was examined with the inconsistency square $\left(\mathrm{I}^{2}\right)$ statistics, with between-study heterogeneity at $\mathrm{I}^{2} \geq 50 \%$ and $p \geq 0.05$ [10]. In case of heterogeneity a random effects model was used [11]. The population risk of CHDs was based on the study by Van der Linde et al. [1].

\section{Results}

The systematic literature search yielded 3029 citations, of which 2736 were excluded by review of the title or abstract. Full manuscripts were retrieved for the remaining 293 studies and a total of 12 articles ( $n=3136$ liveborn twins) were included in the review (Figure 1, Table 1) [12-23]. Eight studies had a prospective design. Six studies included MC twin pregnancies complicated by TTTS only. Four studies only described the prevalence of RVOTO. There was some overlap between the cohorts of Lopriore et al. [18], Hack et al. [14], and Eschbach et al. [13]. Quality assessment is 
summarized in Table 2. To judge the overall risk of bias in each study, it is not recommended to use a summated score for the overall study quality [9]. In the included studies there was a low to moderate risk of bias in the majority of domains. Some studies did not report on their diagnostic tests; prognostic factor measurement was therefore rated as 'high risk of bias'. There was a high risk of bias in the outcome measurement in the study by Hack et al. [14] since the authors only recorded the presence of congenital heart malformations without mentioning whether the method and setting of their investigations to diagnose a CHD was the same for all study participants.

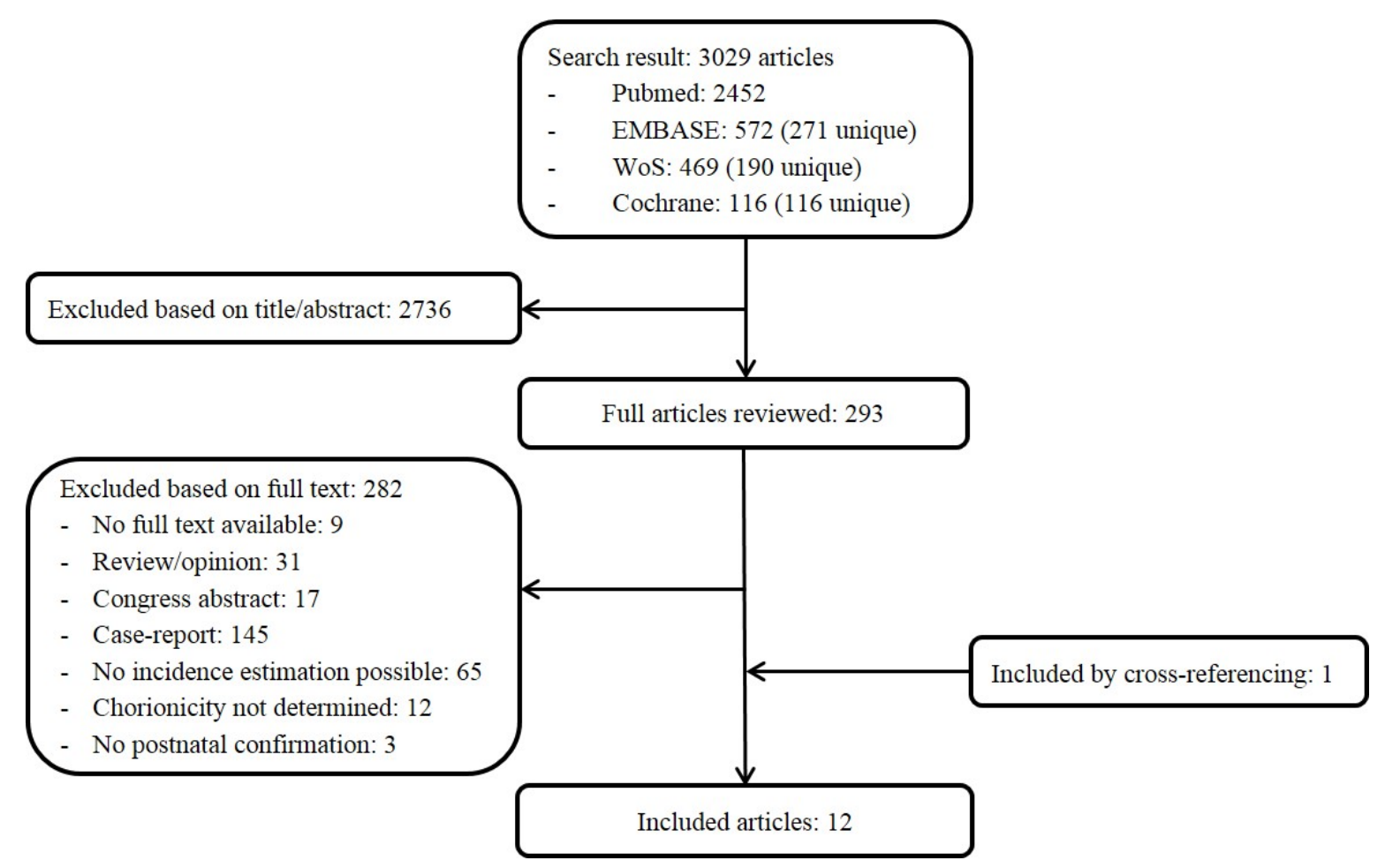

Figure 1. PRISMA diagram for study selection. WoS, Web of Science.

In the study population of 3136 liveborn twins, 185 CHDs were identified. The prevalence of CHDs in MC twins was 59.3 per 1000 live births (95\% CI: 50.5-69.4). In MC twins with and without TTTS, the prevalence of CHDs per 1000 live births was 87.3 (95\% CI: 87.3-140.9) and 3.4 (95\% CI: 44.2-64.5), respectively. Compared to the population prevalence of 9.1 per 1000 live births [1], MC twins were 6.3 times more likely to be born with a CHD than infants in the general population (RR 6.3; 95\% CI: 4.4-9.1). TTTS twins were almost 2.5 times more likely to have a CHD than non-TTTS twins (RR 2.4; 95\% CI: 1.6-3.5). Compared to singletons, TTTS twins had a 12-fold increased risk of having a CHD at birth (RR 12.4, 95\% CI: 8.6-17.8) (Figure 2).

Quintero's classification to stage TTTS severity has been applied since 2000 [24]; studies investigating patient cohorts prior to 2000 therefore do not report Quintero stages. Hidaka et al. [16] describes one TTTS case (Quintero stage 2) where the donor appeared to have CoA after birth. Three of the studies report on the Quintero stage distribution in the study population. In the first study from 2007 [18], with a CHD prevalence of 5.4\% in TTTS twins, the Quintero stage distribution was: $17 \%$ stage I, $37 \%$ stage II, $41 \%$ stage III, $4 \%$ stage IV. In the second study from 2011 [21], with a CHD prevalence of $15.5 \%$, the Quintero stage distribution was: $10 \%$ stage I, $22 \%$ stage II, $50 \%$ stage III, $18 \%$ stage IV. In the third study from 2014 [23], with a CHD prevalence in TTTS twins of $8.9 \%, 30 \%$ of pregnancies were Quintero stage I, $40 \%$ stage II, $21 \%$ stage III, $1 \%$ stage IV, and $7 \%$ stage V. Eschbach et al. [13] found that $82 \%$ of RVOTO cases were staged as Quintero stage III or IV, compared to $43 \%$ of cases without $\operatorname{RVOTO}(p=0.07)$. 
Table 1. Article characteristics.

\begin{tabular}{|c|c|c|c|c|c|c|c|c|c|}
\hline & Year & Author & Country & Time Period & Design & Chorionicity Determination & Study Population & $\begin{array}{l}\text { Number of Liveborn } \\
\text { Twins ( } n \text { TTTS) }\end{array}$ & Number of CHDs \\
\hline 1 & 1996 & Cincotta & UK & 1994-1995 & $\mathrm{P}$ & TTTS diagnosis & 14 TTTS pregnancies & 22 & $\begin{array}{l}\text { 2/10 recipients RVOTO, } \\
\text { donors } 0\end{array}$ \\
\hline 2 & 1998 & Simpson & USA & 1992-1997 & $\mathrm{P}$ & Examination placenta postpartum & 12 TTTS pregnancies & 22 & $\begin{array}{l}\text { 3/10 recipients RVOTO, } \\
\text { donors } 0\end{array}$ \\
\hline 3 & 2001 & Lougheed & Canada & 1994-1998 & $\mathrm{R}$ & TTTS diagnosis & 73 TTTS pregnancies & 146 & $\begin{array}{l}\text { 6/73 recipients RVOTO, } \\
\text { donors } 0\end{array}$ \\
\hline 4 & 2002 & Karatza & UK & 1997-2000 & $\mathrm{P}$ & Examination placenta postpartum & $\begin{array}{c}136 \mathrm{MC} \text { twin } \\
\text { pregnancies (47 TTTS) }\end{array}$ & $226(60)$ & $\begin{array}{l}\text { 9/226 MC twins, no-TTTS } \\
\text { 4/166, TTTS 5/60 }\end{array}$ \\
\hline 5 & 2006 & Herberg & Germany & 1995-1997 & $\mathrm{P}$ & TTTS diagnosis, treated with FLS & 73 TTTS pregnancies & 89 & 10/89 TTTS twins \\
\hline 6 & 2007 & Hidaka & Japan & $2000-2006$ & $\mathrm{P}$ & Examination placenta postpartum & $\begin{array}{c}87 \mathrm{MC} \text { twin } \\
\text { pregnancies (1 TTTS) }\end{array}$ & $174(2)$ & 11/174 MC twins \\
\hline 7 & 2007 & Lopriore & Netherlands & 2002-2005 & $\mathrm{P}$ & Examination placenta postpartum & $\begin{array}{c}101 \mathrm{MC} \text { twin } \\
\text { pregnancies (46 TTTS) }\end{array}$ & $161(74)$ & $\begin{array}{c}\text { 6/161 MC twins, no-TTTS } \\
\text { 2/87, TTTS 4/74 }\end{array}$ \\
\hline 8 & 2009 & Hack & Netherlands & $2000-2007$ & $\mathrm{R}$ & $\begin{array}{l}\text { First trimester ultrasound scan } \\
\text { and/or examination placenta } \\
\text { postpartum }\end{array}$ & $\begin{array}{l}98 \text { MCMA twin } \\
\text { pregnancies (6 TTTS) }\end{array}$ & 164 (unknown) & 7/164 MC twins \\
\hline 9 & 2011 & Pruetz & USA & $2009-2010$ & $\mathrm{P}$ & TTTS diagnosis, all treated with FLS & 50 TTTS pregnancies & 84 & 13/84 TTTS twins \\
\hline 10 & 2013 & Pettit & USA & 1996-2003 & $\mathrm{R}$ & Examination placenta postpartum & $\begin{array}{c}482 \mathrm{MC} \text { twin } \\
\text { pregnancies (48 TTTS) }\end{array}$ & $926(83)$ & $\begin{array}{c}\text { 69/926 MC twins, } \\
\text { no-TTTS 55/843, TTTS } \\
14 / 83\end{array}$ \\
\hline 11 & 2014 & Springer & Austria & 2002-2012 & $\mathrm{R}$ & $\begin{array}{c}\text { First trimester scan, TTTS treated } \\
\text { with FLS }\end{array}$ & $\begin{array}{c}381 \mathrm{MC} \text { twin } \\
\text { pregnancies (70 TTTS) }\end{array}$ & $754(135)$ & $\begin{array}{c}\text { 39/754 MC twins, } \\
\text { no-TTTS 27/619, TTTS } \\
12 / 135\end{array}$ \\
\hline 12 & 2016 & Eschbach & Netherlands & 2004-2015 & $P$ & $\begin{array}{c}\text { TTTS diagnosis, majority treated } \\
\text { with FLS }\end{array}$ & 485 TTTS pregnancies & 368 (368 recipients) & 11/368 recipients RVOTO \\
\hline
\end{tabular}

P, prospective; R, retrospective; FLS, fetoscopic laser surgery; TTTS, twin-twin transfusion syndrome; CHDs, congenital heart defects; MC, monochorionic; RVOTO, right ventricular outflow tract obstruction. 
Table 2. Quality scores based on the Hayden bias rating tool.

\begin{tabular}{|c|c|c|c|c|c|c|c|}
\hline & Variable/Study & $\begin{array}{c}\text { Study } \\
\text { Participation }\end{array}$ & Study Attrition & $\begin{array}{c}\text { Prognostic Factor } \\
\text { Measurement }\end{array}$ & Outcome Measurement & Study Confounding & $\begin{array}{c}\text { Statistical Analysis and } \\
\text { Reporting }\end{array}$ \\
\hline 1 & Cincotta & Moderate & Moderate & High & Moderate & Low & Low \\
\hline 2 & Simpson & Low & Low & Low & Moderate & Low & Low \\
\hline 3 & Lougheed & Moderate & Moderate & High & Low & Low & Moderate \\
\hline 4 & Karatza & Low & Low & Low & Low & Low & Moderate \\
\hline 5 & Herberg & Low & Low & Low & Low & Low & Low \\
\hline 6 & Hidaka & Moderate & Low & Moderate & Moderate & Low & Low \\
\hline 7 & Lopriore & Low & Low & Low & Low & Low & Low \\
\hline 8 & Hack & Low & High & Moderate & High & Low & Moderate \\
\hline 9 & Pruetz & Low & Low & Moderate & Low & Low & Low \\
\hline 10 & Pettit & Low & Low & Moderate & Low & Low & Low \\
\hline 11 & Springer & Low & Moderate & Low & Moderate & Low & Moderate \\
\hline 12 & Eschbach & Low & Moderate & Low & Moderate & Low & Low \\
\hline
\end{tabular}


A

Risk Ratio

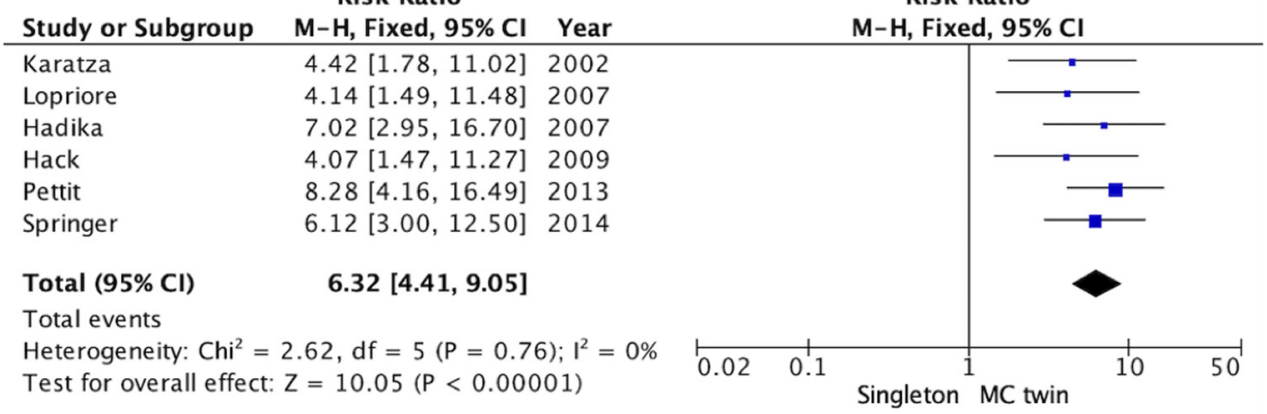

B

Study or Subgroup

\section{Karatza}

Herberg

Lopriore

Pruetz

Pettit

Springer

Total $(95 \% \mathrm{Cl})$

Total events

Heterogeneity: $\mathrm{Chi}^{2}=3.61, \mathrm{df}=5(\mathrm{P}=0.61) ; \mathrm{I}^{2}=0 \%$

Test for overall effect: $Z=13.56(P<0.00001)$

C

Risk Ratio

Study or Subgroup $\mathrm{M}-\mathrm{H}$, Fixed, $95 \% \mathrm{Cl}$ Year

Karatza 2.68 $[0.83,8.59] 2002$

Lopriore $\quad 2.55[0.56,11.64] 2007$

Hadika $\quad 7.06[2.97,16.80] 2007$

Pettit $\quad 7.25[3.60,14.58] 2013$

Springer

Total $(95 \% \mathrm{Cl})$

$5.18[2.47,10.87] 2014$

Total $(\mathbf{9 5 \%} \mathrm{CI})$
Total events

Heterogeneity: $\mathrm{Chi}^{2}=3.45, \mathrm{df}=4(\mathrm{P}=0.48) ; \mathrm{I}^{2}=0 \%$

Test for overall effect: $Z=8.41(P<0.00001)$

\section{$5.72[3.81,8.59]$}

D

\begin{tabular}{lrl} 
Study or Subgroup & $\begin{array}{r}\text { Risk Ratio } \\
\text { M-H, Fixed, 95\% Cl }\end{array}$ & Year \\
\hline Karatza & $3.46[0.96,12.45]$ & 2002 \\
Lopriore & $2.35[0.44,12.48]$ & 2007 \\
Pettit & $2.59[1.50,4.44]$ & 2013 \\
Springer & $1.99[1.06,3.73]$ & 2014 \\
& & \\
Total $(\mathbf{9 5 \%} \mathrm{Cl})$ & $\mathbf{2 . 3 9}[\mathbf{1 . 6 2}, \mathbf{3 . 5 0}]$ \\
Total events & \\
Heterogeneity: Chi $^{2}=0.73, \mathrm{df}=3(\mathrm{P}=0.87) ; \mathrm{I}^{2}=0 \%$ \\
Test for overall effect: $\mathrm{Z}=4.44(\mathrm{P}<0.00001)$
\end{tabular}

\section{Risk Ratio}

$35[0.44,12.48] 2007$

. $59[1.50,4.44] 2013$

$2.39[1.62,3.50]$

Test for overall effect: $Z=4.44(P<0.00001)$

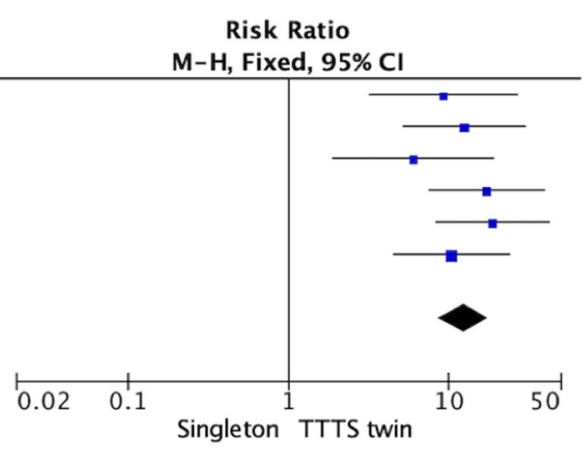

Risk Ratio M-H, Fixed, 95\% Cl

Risk Ratio M-H, Fixed, 95\% CI

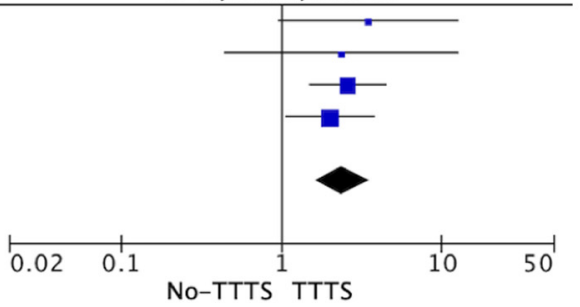

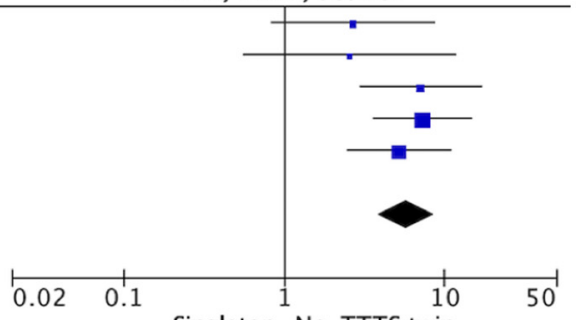

Figure 2. Risk of CHDs in MC twins with and without TTTS. (A) MC twins vs. singletons, (B) MC twins with TTTS vs. singletons, (C) MC twins without TTTS vs. singletons, (D) MC twins with TTTS vs. MC twins without TTTS. Risk ratios with 95\% confidence intervals (CIs) were calculated by a fixed effect model. The pooled risk ratio is represented by a black diamond, where diamond width corresponds to $95 \%$ CI bounds.

The reported birth prevalence of the CHD subtypes in all MC twins (per 1000 live births) was: VSD, 25.9 (95\% CI: 20.2-33.2); RVOTO, 22.3 (95\% CI: 17.6-28.4); ASD, 13.6 (95\% CI: 9.7-19.1); CoA, 2.1 (95\% CI: 0.9-5.0); AS, 2.6 (95\% CI: 1.2-5.6); TOF, 0.9 (95\% CI: 0.2-3.1), and TGA, 0.9 (95\% CI: 0.2-3.1). The prevalence of TOF and TGA was similar to the prevalence in singletons (both 0.3 per 1000 singleton live births). All other subtypes had a higher prevalence $(p<0.05)$. The type of CHD with the largest relative risk (RR 70; 95\% CI: 27-179, $p<0.001)$ in TTTS twins was RVOTO (35/1000 vs. 0.5/1000 singleton live births). 


\section{Discussion}

With this systematic review and meta-analysis, we estimated the prevalence of CHD in MC twins to be 59 per 1000 live births, which is over 6 times higher as compared to singleton live births. In TTTS survivors the risk is even higher, with a 12 -fold increased risk compared to singletons. The estimated prevalence in these neonates is 87 per 1000 live births. Therefore, we recommend an expert fetal echocardiogram in all MC twins at mid-gestation. In the event of TTTS, a second prenatal fetal echocardiogram around 30-32 weeks should be performed to rule out any acquired defects such as RVOTO, and a postnatal echocardiogram in all survivors may be considered.

The estimated prevalence rates and relative risks in this study are lower than those previously reported by Bahtiyar et al. [3]. There may be several explanations for this. First, the present study involves over 5 times the number of live birth MC twins, which enabled us to estimate the birth prevalence of CHD in MC twins with and without TTTS more precisely, and which possibly reduced the risk of selection bias. Second, we excluded stillbirths. The inclusion of stillborn fetuses would have elevated the prevalence of CHD. Finally, lower relative risks were calculated due to the use of the generally accepted population prevalence of CHDs of 9.1 per 1000 live births [1] instead of the lower rates from the cohorts of Wren et al. [25] or Ferenc et al. [26].

Twin birth rates have increased over the last decades due to the increasing maternal age and the extensive use of assisted reproductive technology (ART) $[27,28]$. ART increases not only the number of dizygotic but also the number of monozygotic twins. In MC twins, which are all monozygotic, the division of the fertilized ovum is hypothesized to be an influencing factor which could contribute to primary structural cardiac anomalies [29]. ART itself is also considered a risk factor for CHDs [30,31]. However, the increased incidence of acquired CHDs in MC twins has mostly been attributed to MC placentation and TTTS, indicating an influence of hemodynamic alterations on cardiac development. We found an increased risk of the most prevalent subtypes of CHDs (VSD, RVOTO, ASD, CoA, and AS) in $\mathrm{MC}$ twins compared with singletons, although this should be interpreted with caution due to the low numbers of some CHDs, particularly CoA and AS. However, this finding possibly supports the hypothesis of the influence of hemodynamic factors in the development of CHDs, which is furthermore supported by the fact that defects such as TOF, for which genetic influences are thought to be more important in development, are equally prevalent in $\mathrm{MC}$ twins and singletons. Previous studies suggest that more severe TTTS is associated with cardiac defects [4,32,33], possibly indicating an effect of a larger hemodynamic imbalance. This finding could not be supported by this meta-analysis since only a small number of studies report on the Quintero stage distribution $[18,21,23]$, and in only one study the disease severity was analyzed in relation to CHD prevalence [13].

Fetoscopic laser surgery, as a curative treatment for TTTS, ensures cardiovascular improvement in affected twins [34-36] but does not prevent the occurrence of cardiac defects at birth in all cases, as shown by this study. Cardiac adaptation in TTTS mainly occurs in recipients [23,37]. Cardiac overload and hypervolemia in these twins may result in shear stress and ventricular hypertrophy, which can cause abnormal development of the cardiac valves through a cascade of events. Shear stress causes endothelial changes, and right ventricular hypertrophy and severe tricuspid valve regurgitation lead to diminished flow across the right ventricular outflow tract, which may impair growth and development of the right ventricular outflow tract. These processes can lead to RVOTO, which is found in approximately $3.5 \%$ of recipients (this study). It is suggested that since valve development is not completed at the beginning of the second trimester, fetuses who experience TTTS earlier in gestation are more frequently affected by RVOTO [13].

Less reported, but still clinically important, is the coexistence of CoA and TTTS, which seems to be more frequently seen in donors than in recipients [38]. The underlying mechanism leading to $\mathrm{CoA}$ is not fully understood. A proposed explanation is the reduced flow theory, which suggests that the narrowing of the aortic arch develops secondary to hemodynamic disturbances [39]. Decreased flow may occur as the result of decreased left-sided cardiac output of the donor twin in TTTS due to hypovolemia, or in the case of ventricular outflow tract obstruction [40]. 
Improved echocardiographic techniques are likely to substantially account for the increased detection rate of cardiac lesions. In the last decade there has been a shift towards a diagnosis before birth. In expert hands, prenatal detection rates of CHD in multiple pregnancies can be as high as $88 \%$ [41]. However, in the case of TTTS, the CHD detection rates are reported to be as low as $42.9 \%$ in recipient twins and $16.7 \%$ in donor twins [21]. Possible explanations for the low detection rates are the polyhydramnios in combination with the excessive movements of the recipient twin and the 'stuck' anhydramniotic donor, which both severely impair image acquisition and the detection of CHD. Therefore, next to the detection of possible acquired valvular pathology, follow-up fetal echocardiograms are warranted after TTTS treatment, when scanning conditions normalize, to rule out missed structural anomalies at earlier scans. An accurate diagnosis is critical in determining the requirement of immediate (postnatal) treatment, predicting the course of (surgical) repair, and for the counseling the parents about the prognosis.

This study has certain limitations. There are only a few studies with a large sample size available. Comparisons of prevalence rates of all CHD subtypes between MC twins with and without TTTS and between MC twins and singletons are therefore limited. We found a high incidence of CHDs in MC twins, especially in the TTTS population, but it is possible that many milder forms of CHDs are present in twins without TTTS and in singletons that are missed or underdiagnosed, which could lead to an underestimation of the CHD prevalence in these infants. In this review, hospital-based studies were included which could have resulted in upwardly biased estimates of prevalence compared to national registries. Our data do not reflect the CHD prevalence at mid-gestation, since (selective) feticide cases and studies without postnatal follow-up were excluded. We do not think, however, that the inclusion of the (limited number of) feticide cases would have changed our results significantly. Despite these limitations, our results do suggest a significant burden of CHDs in MC twins that can have important neonatal implications. Future studies should determine whether there is still a need to perform postnatal echocardiography in all TTTS twins.

\section{Conclusions}

There is still a large burden of CHDs in MC twins with and without TTTS. We recommend an expert fetal echocardiogram in all MC twins, follow-up scans in the event of TTTS, and a postnatal cardiac evaluation in all TTTS survivors.

Author Contributions: Conceptualization, M.G. and M.C.H.; methodology, M.G.; formal analysis, M.G. and M.R.S.; writing—original draft preparation, M.G. and M.R.S.; writing—review and editing, M.G., M.R.S., A.D.J.T.H., D.O. and M.C.H.; supervision, M.G and M.C.H.

Conflicts of Interest: The authors declare no conflict of interest.

\section{References}

1. Van der Linde, D.; Konings, E.E.; Slager, M.A.; Witsenburg, M.; Helbing, W.A.; Takkenberg, J.J; Roos-Hesselink, J.W. Birth prevalence of congenital heart disease worldwide: A systematic review and meta-analysis. J. Am. Coll. Cardiol. 2011, 58, 2241-2247. [CrossRef]

2. Best, K.E.; Rankin, J. Increased risk of congenital heart disease in twins in the North of England between 1998 and 2010. Heart 2015, 101, 1807-1812. [CrossRef]

3. Bahtiyar, M.O.; Dulay, A.T.; Weeks, B.P.; Friedman, A.H.; Copel, J.A. Prevalence of congenital heart defects in monochorionic/diamniotic twin gestations: A systematic literature review. J. Ultrasound Med. 2007, 26, 1491-1498. [CrossRef]

4. Michelfelder, E.; Tan, X.; Cnota, J.; Divanovic, A.; Statile, C.; Lim, F.Y.; Crombleholme, T. Prevalence, Spectrum, and Outcome of Right Ventricular Outflow Tract Abnormalities in Twin-twin Transfusion Syndrome: A Large, Single-center Experience. Congenit. Heart Dis. 2015, 10, 209-218. [CrossRef]

5. Lopriore, E.; Vandenbussche, F.P.; Tiersma, E.S.; de Beaufort, A.J.; de Leeuw, J.P. Twin-to-twin transfusion syndrome: New perspectives. J. Pediatr. 1995, 127, 675-680. [CrossRef] 
6. Huber, A.; Hecher, K. How can we diagnose and manage twin-twin transfusion syndrome? Best Pract. Res. Clin. Obstet. Gynaecol. 2004, 18, 543-556. [CrossRef]

7. Hecher, K.; Gardiner, H.M.; Diemert, A.; Bartmann, P. Long-term outcomes for monochorionic twins after laser therapy in twin-to-twin transfusion syndrome. Lancet Child Adolesc. Health 2018, 2, 525-535. [CrossRef]

8. Moher, D.; Liberati, A.; Tetzlaff, J.; Altman, D.G.; Group, P. Preferred reporting items for systematic reviews and meta-analyses: The PRISMA statement. J. Clin. Epidemiol. 2009, 62, 1006-1012. [CrossRef]

9. Hayden, J.A.; van der Windt, D.A.; Cartwright, J.L.; Cote, P.; Bombardier, C. Assessing bias in studies of prognostic factors. Ann. Intern. Med. 2013, 158, 280-286. [CrossRef]

10. Higgins, J.P.; Thompson, S.G.; Deeks, J.J.; Altman, D.G. Measuring inconsistency in meta-analyses. BMJ 2003, 327, 557-560. [CrossRef]

11. DerSimonian, R.; Laird, N. Meta-analysis in clinical trials. Control Clin Trials 1986, 7, 177-188. [CrossRef]

12. Cincotta, R.; Oldham, J.; Sampson, A. Antepartum and postpartum complications of twin-twin transfusion. Aust. N. Z. J. Obstet. Gynaecol. 1996, 36, 303-308. [CrossRef]

13. Eschbach, S.J.; Boons, L.; Van Zwet, E.; Middeldorp, J.M.; Klumper, F.; Lopriore, E.; Teunissen, A.K.K.; Rijlaarsdam, M.E.; Oepkes, D.; Ten Harkel, A.D.J.; et al. Right ventricular outflow tract obstruction in complicated monochorionic twin pregnancy. Ultrasound Obstet. Gynecol. 2017, 49, 737-743. [CrossRef]

14. Hack, K.E.; Derks, J.B.; Schaap, A.H.; Lopriore, E.; Elias, S.G.; Arabin, B.; Eggink, A.J.; Sollie, K.M.; Mol, B.W.J.; Duvekot, H.J.; et al. Perinatal outcome of monoamniotic twin pregnancies. Obstet. Gynecol. 2009, 113, 353-360. [CrossRef]

15. Herberg, U.; Gross, W.; Bartmann, P.; Banek, C.S.; Hecher, K.; Breuer, J. Long term cardiac follow up of severe twin to twin transfusion syndrome after intrauterine laser coagulation. Heart 2006, 92, 95-100. [CrossRef]

16. Hidaka, N.; Tsukimori, K.; Chiba, Y.; Hara, T.; Wake, N. Monochorionic twins in which at least one fetus has a congenital heart disease with or without twin-twin transfusion syndrome. J. Perinat. Med. 2007, 35, 425-430. [CrossRef]

17. Karatza, A.A.; Wolfenden, J.L.; Taylor, M.J.; Wee, L.; Fisk, N.M.; Gardiner, H.M. Influence of twin-twin transfusion syndrome on fetal cardiovascular structure and function: Prospective case-control study of 136 monochorionic twin pregnancies. Heart 2002, 88, 271-277. [CrossRef]

18. Lopriore, E.; Bokenkamp, R.; Rijlaarsdam, M.; Sueters, M.; Vandenbussche, F.P.; Walther, F.J. Congenital heart disease in twin-to-twin transfusion syndrome treated with fetoscopic laser surgery. Congenit. Heart Dis. 2007, 2, 38-43. [CrossRef]

19. Lougheed, J.; Sinclair, B.G.; Fung Kee Fung, K.; Bigras, J.L.; Ryan, G.; Smallhorn, J.F.; Hornberger, L.K. Acquired right ventricular outflow tract obstruction in the recipient twin in twin-twin transfusion syndrome. J. Am. Coll. Cardiol. 2001, 38, 1533-1538. [CrossRef]

20. Pettit, K.E.; Merchant, M.; Machin, G.A.; Tacy, T.A.; Norton, M.E. Congenital heart defects in a large, unselected cohort of monochorionic twins. J. Perinatol. 2013, 33, 457-461. [CrossRef]

21. Pruetz, J.D.; Sklansky, M.; Detterich, J.; Korst, L.M.; Llanes, A.; Chmait, R.H. Twin-twin transfusion syndrome treated with laser surgery: Postnatal prevalence of congenital heart disease in surviving recipients and donors. Prenat. Diagn. 2011, 31, 973-977. [CrossRef]

22. Simpson, L.L.; Marx, G.R.; Elkadry, E.A.; D'Alton, M.E. Cardiac dysfunction in twin-twin transfusion syndrome: A prospective, longitudinal study. Obstet. Gynecol. 1998, 92, 557-562. [CrossRef]

23. Springer, S.; Mlczoch, E.; Krampl-Bettelheim, E.; Mailath-Pokorny, M.; Ulm, B.; Worda, C.; Worda, K. Congenital heart disease in monochorionic twins with and without twin-to-twin transfusion syndrome. Prenat. Diagn. 2014, 34, 994-999. [CrossRef]

24. Quintero, R.A.; Morales, W.J.; Allen, M.H.; Bornick, P.W.; Johnson, P.K.; Kruger, M. Staging of twin-twin transfusion syndrome. J. Perinatol. 1999, 19, 550-555. [CrossRef]

25. Wren, C.; Richmond, S.; Donaldson, L. Temporal variability in birth prevalence of cardiovascular malformations. Heart 2000, 83, 414-419. [CrossRef]

26. Ferencz, C. On the birth prevalence of congenital heart disease. J. Am. Coll. Cardiol. 1990, 16, 1701-1702. [CrossRef]

27. Blondel, B.; Kaminski, M. Trends in the occurrence, determinants, and consequences of multiple births. Semin. Perinatol. 2002, 26, 239-249. [CrossRef]

28. Martin, J.A.; Hamilton, B.E.; Osterman, M.J. Three Decades of Twin Births in the United States, 1980-2009; NCHS Data Brief; U.S. Department of Health \& Human Services: Washington, DC, USA, 2012; pp. 1-8. 
29. Burn, J.; Corney, G. Congenital heart defects and twinning. Acta Genet. Med. Gemellol. (Roma) 1984, 33, 61-69. [CrossRef]

30. Giorgione, V.; Parazzini, F.; Fesslova, V.; Cipriani, S.; Candiani, M.; Inversetti, A.; Sigismondi, C.; Tiberio, F.; Cavoretto, P. Congenital heart defects in IVF/ICSI pregnancy: Systematic review and meta-analysis. Ultrasound Obstet. Gynecol. 2018, 51, 33-42. [CrossRef]

31. Panagiotopoulou, O.; Fouzas, S.; Sinopidis, X.; Mantagos, S.P.; Dimitriou, G.; Karatza, A.A. Congenital heart disease in twins: The contribution of type of conception and chorionicity. Int. J. Cardiol. 2016, 218, 144-149. [CrossRef]

32. Michelfelder, E.; Gottliebson, W.; Border, W.; Kinsel, M.; Polzin, W.; Livingston, J.; Khoury, P.; Crombleholme, T. Early manifestations and spectrum of recipient twin cardiomyopathy in twin-twin transfusion syndrome: Relation to Quintero stage. Ultrasound Obstet. Gynecol. 2007, 30, 965-971. [CrossRef]

33. Barrea, C.; Alkazaleh, F.; Ryan, G.; McCrindle, B.W.; Roberts, A.; Bigras, J.L.; Barrett, J.; Seaward, G.P.; Smallhorn, J.F.; Hornberger, L.K. Prenatal cardiovascular manifestations in the twin-to-twin transfusion syndrome recipients and the impact of therapeutic amnioreduction. Am. J. Obstet. Gynecol. 2005, 192, 892-902. [CrossRef]

34. Moon-Grady, A.J.; Rand, L.; Lemley, B.; Gosnell, K.; Hornberger, L.K.; Lee, H. Effect of selective fetoscopic laser photocoagulation therapy for twin-twin transfusion syndrome on pulmonary valve pathology in recipient twins. Ultrasound Obstet. Gynecol. 2011, 37, 27-33. [CrossRef]

35. Sueters, M.; Middeldorp, J.M.; Vandenbussche, F.P.; Teunissen, K.A.; Lopriore, E.; Kanhai, H.H.; Le Cessie, S.; Oepkes, D. The effect of fetoscopic laser therapy on fetal cardiac size in twin-twin transfusion syndrome. Ultrasound Obstet. Gynecol. 2008, 31, 158-163. [CrossRef]

36. Barrea, C.; Hornberger, L.K.; Alkazaleh, F.; McCrindle, B.W.; Roberts, A.; Berezovska, O.; Windrim, R.; Seaward, P.G.; Smallhorn, J.F.; Ryan, G. Impact of selective laser ablation of placental anastomoses on the cardiovascular pathology of the recipient twin in severe twin-twin transfusion syndrome. Am. J. Obstet. Gynecol. 2006, 195, 1388-1395. [CrossRef]

37. Van Mieghem, T.; Martin, A.M.; Weber, R.; Barrea, C.; Windrim, R.; Hornberger, L.K.; Jaeggi, E.; Ryan, G. Fetal cardiac function in recipient twins undergoing fetoscopic laser ablation of placental anastomoses for Stage IV twin-twin transfusion syndrome. Ultrasound Obstet. Gynecol. 2013, 42, 64-69. [CrossRef]

38. van den Boom, J.; Battin, M.; Hornung, T. Twin-twin transfusion syndrome, coarctation of the aorta and hypoplastic aortic arch: A case series report. J. Paediatr. Child Health 2010, 46, 76-79. [CrossRef]

39. Buyens, A.; Gyselaers, W.; Coumans, A.; Al Nasiry, S.; Willekes, C.; Boshoff, D.; Frijns, J.P.; Witters, I. Difficult prenatal diagnosis: Fetal coarctation. Facts Views Vis. ObGyn 2012, 4, 230-236.

40. Rudolph, A.M.; Heymann, M.A.; Spitznas, U. Hemodynamic considerations in the development of narrowing of the aorta. Am. J. Cardiol. 1972, 30, 514-525. [CrossRef]

41. Paladini, D.; Vassallo, M.; Sglavo, G.; Russo, M.G.; Martinelli, P. Diagnosis and outcome of congenital heart disease in fetuses from multiple pregnancies. Prenat. Diagn. 2005, 25, 403-406. [CrossRef]

(C) 2019 by the authors. Licensee MDPI, Basel, Switzerland. This article is an open access article distributed under the terms and conditions of the Creative Commons Attribution (CC BY) license (http://creativecommons.org/licenses/by/4.0/). 